\title{
PERBANDINGAN PENGUKURAN MANUAL DAN SIMULASI MODEL TIME-VARYING UNTUK SUHU DAN ALIRAN UDARA
}

\author{
Maharani \\ Program Studi Matematika, Fakultas Sains dan Tekink \\ Universitas Jenderal Soedirman, Purwokerto.
}

\begin{abstract}
Considering the natural ventilation, the thermal behavior of buildings can be described by time-varying model. In this paper, we describe an implementation of model linear time-varying systems.

We show the consequences of the model on computing time and accuracy. Finally, we compare experimental measures and simulation results using time-varying systems model. The model shows negligible difference in accuracy, and the computing time shortens.
\end{abstract}

Keywords. time-varying systems, reduced systems, experimental measures.

\section{PENDAHULUAN}

Pada masa sekarang ini, sebagian besar alat numerik digunakan untuk melakukan simulasi terhadap kelakuan udara ruangan, misalkan untuk beberapa fenomena fisika : aliran udara, kelembaban, dan sebagainya. Keragaman masalah muncul secara simultan dengan beberapa kemungkinan penyelesaian perhitungan. Perhitungan - perhitungan yang rumit tersebut dapat diselesaikan dengan bantuan komputer. Masih sangat terbuka tantangan untuk membuat suatu model yang dapat mempersingkat waktu perhitungan dan proses perhitungan.

Sistem model tereduksi telah menjadi topik utama penelitian para teknisi sejak awal tahun 1980-an. Tujuan dari reduksi sistem adalah menyediakan sistem yang lebih simpel bagi pengguna, namun lebih akurat dan tepat, untk menyelesaikan perhitungan - perhitungan sederhana misalnya dalam hal simulasi perubahan sistem yang dinamis, perhitungan dalam hukum - hukum kendali sistem. Teknik model tereduksi sering digunakan dalam bidang pemodelan suhu ruangan (Palomo, 1997).

Setelah melalui tahap diskretisasi maka model pengukuan suhu ruangan masih merupakan sistem linear yang besar. Metode yang akurat dari model tereduksi sangat dimungkinkan untuk sistem time-invariant (sistem yang tak

Diterima 15 Januari 2009, disetujui untuk dipublikasikan 21 April 2009. 
bergantung waktu). Tapi pada kasus tertentu dalam pengukuran aliran udara, model suhu udara menjadi sistem time-varying (sistem yang bergantung waktu), disebabkan oleh kecepatan aliran udara antar ruangan dalam suatu bangunan (Boyer, 1998).

Dalam penelitian ini akan dikembangkan suatu model pengukuran suhu dan aliran udara pada ruangan dengan menggunakan pendekatan sistem linear time-varying yang direduksi. Selanjutnya, model tersebut disimulasikan menggunakan software MatLab agar pengukuran suhu dan aliran udara lebih valid. Keefektifan dari model dapat dilihat setelah diaplikasikan dalam ruangan multi zone. Hasil penelitian ini diharapkan dapat menjadi alternatif lain dalam perhitungan suhu ruangan dan aliran udara selain menggunakan alat yang manual, karena model yang dihasilkan merupakan model reduksi yang dapat mempersingkat waktu dan perhitungannya lebih akurat.

\section{METODOLOGI PENELITIAN}

Penelitian ini menganalisis perbandingan model linear time varying orde penuh dan model linear time-varying yang tereduksi. Langkah pertama adalah pengambilan data dengan mengukur secara manual temperatur suatu ruangan, ini dilakukan selama 7 hari kerja. Selanjutnya data yang diperoleh digunakan sebagai input untuk membuat simulasi menggunakan model time-varying dengan bantuan software MatLab agar pengukuran suhu dan aliran udara lebih valid.

\section{Tahap - tahap Penelitian}

Tahap pertama adalah mempersiapkan alat dan mengumpulkan bahan pustaka yang berkaitan sengan sistem linear time-varying, model pengukuran suhu dan aliran udara dalam ruangan, dan simulasi komputer.

Tahap kedua terdiri dari dua kegiatan. Kegiatan pertama akan dilakukan analisa model sistem linear time-vaying standar dan model terreduksi untuk pengukuran suhu ruangan. Pengukuran dilakukan pada suatu bangunan yang terdiri dari 5 ruangan, yaitu 1 ruang keluarga, 3 ruang tidur, dan 1 dapur. 
Pengukuran dilakukan dengan dua jenis ruangan, yaitu ruangan tertutup dan terbuka.

Untuk pengukuran pada ruang tertutup dilakukan dengan cara :

a. semua pintu dan jendela ruangan ditutup selama 7 hari, selanjutnya dilakukan pengukuran manual.

b. model aliran udara diabaikan, sehingga model suhunya time-invariant

c. dilakukan simulasi komputer menggunakan model standar dan model tereduksi.

Untuk pengukuran pada ruangan terbuka dilakukan denga cara :

a. Pintu dalam ruang keluarga dan jendela dari 2 ruang tidur ditutup, pintu antara 2 ruang tidur dan ruang keluarga dibuka, selanjutnya udara dapat bersikulasi dalam ruang tersebut. Kemudian dilakukan pengukuran secara manual.

b. Pada kasus ini model suhunya adalah time-varying.

c. Dilakukan simulasi komputer menggunakan model satndar dan model terreduksi dengan metode model terreduksi terpisah.

Kegiatan kedua akan dilakukan perbandingan ukuran dan simulasi temperatur ruangan agar merelatifkan perbedaan antara pengukuran manual dengan model standar dan model terreduksi.

Dari semua pengukuran tersebut yang dicatat adalah perhitungan waktu, tingkat error terreduksi, perbedaan suhu, dan standar deviasinya.

Tahap ketiga, kegiatannya adalah membuat rangkuman dan kesimpulan dari pelaksanaan penelitian, serta membuat laporan hasil penelitian.

\section{HASIL DAN PEMBAHASAN}

Penelitian dilakukan dalam tiga tahap. Pada tahap pertama diperoleh hasil pengumpulan data sebagai berikut. 


\begin{tabular}{|c|r|r|}
\hline \multirow{2}{*}{ Jam } & \multicolumn{2}{|c|}{ Temperatur } \\
\cline { 2 - 3 } & Manual & \multicolumn{1}{c|}{ Model } \\
\hline 0 & 32 & \multicolumn{1}{|c|}{31,8} \\
\hline 1 & 31,92 & 31,62 \\
\hline 2 & 31,6 & 31,52 \\
\hline 3 & 31,33 & 31,4 \\
\hline 4 & 31,45 & 31,3 \\
\hline 5 & 31,65 & 31,15 \\
\hline 6 & 31,79 & 31,09 \\
\hline 7 & 31,58 & 31,12 \\
\hline 8 & 31,57 & 31,27 \\
\hline 9 & 31,48 & 31,48 \\
\hline 10 & 31,77 & 31,77 \\
\hline 11 & 32,03 & 32,13 \\
\hline 12 & 32,18 & 32,58 \\
\hline 13 & 32,27 & 32,87 \\
\hline 14 & 32,39 & 33 \\
\hline 15 & 32,2 & 32,9 \\
\hline 16 & 32,09 & 32,81 \\
\hline 17 & 32,15 & 32,85 \\
\hline 18 & 32,22 & 32,81 \\
\hline 19 & 32,26 & 32,66 \\
\hline 20 & 32,35 & 32,49 \\
\hline 21 & 32,38 & 32,34 \\
\hline 22 & 32,47 & 32,17 \\
\hline 23 & 32,42 & 32,02 \\
\hline 24 & 32,33 & 31,93 \\
\hline
\end{tabular}

\begin{tabular}{|r|r|r|}
\hline \multirow{2}{*}{ Jam } & \multicolumn{2}{|c|}{ Temperatur } \\
\cline { 2 - 3 } & \multicolumn{1}{|c|}{ Manual } & \multicolumn{1}{c|}{ Model } \\
\hline 25 & 32,08 & \multicolumn{1}{c|}{31,8} \\
\hline 26 & 31,82 & 31,72 \\
\hline 27 & 31,69 & 31,69 \\
\hline 28 & 31,52 & 31,62 \\
\hline 29 & 31,63 & 31,52 \\
\hline 30 & 31,84 & 31,4 \\
\hline 31 & 31,36 & 31,31 \\
\hline 32 & 31,72 & 31,2 \\
\hline 33 & 32,22 & 31,28 \\
\hline 34 & 32,11 & 31,21 \\
\hline 35 & 32,08 & 31,27 \\
\hline 36 & 31,34 & 31,48 \\
\hline 37 & 31,55 & 31,77 \\
\hline 38 & 32,45 & 32,13 \\
\hline 39 & 32,58 & 32,58 \\
\hline 40 & 32,3 & 32,97 \\
\hline 41 & 32,16 & 33,16 \\
\hline 42 & 32,2 & 33,2 \\
\hline 43 & 32,11 & 33,11 \\
\hline 44 & 32,42 & 32,95 \\
\hline 45 & 32,51 & 32,81 \\
\hline 46 & 32,36 & 32,66 \\
\hline 47 & 32,23 & 32,49 \\
\hline 48 & 32,05 & 32,34 \\
\hline & & \\
\hline & & \\
\hline
\end{tabular}


Selanjutnya, data yang ada tersebut digunakan sebagai input untuk melakukan simulasi dari suatu model suhu dan aliran udara yaitu model timevarying.

Secara umum, model time-varying untuk suhu dan aliran udara adalah (Boyer, 1999)

$$
\begin{array}{lll}
\dot{\boldsymbol{T}}=\boldsymbol{A}(\boldsymbol{t}) \boldsymbol{T}+\boldsymbol{B}(\boldsymbol{t}) \boldsymbol{u} & \\
\text { dengan } & \boldsymbol{T} & \text { : output dari sistem } \\
& \boldsymbol{A}(\boldsymbol{t}), \boldsymbol{B}(\boldsymbol{t}) & \text { : matriks fungsi dalam } \mathrm{t} \\
\boldsymbol{u} & \text { : input dari sistem }
\end{array}
$$

Sistem (1) merupakan sistem dengan full order yang melibatkan perhitungan variabel seperti temperatur, tenaga panas tiap jam, dalam waktu 1 periode.

Persamaan (1) ditransformasikan dengan mengubah variabel - variabel ke state yang baru, yaitu :

$$
\begin{aligned}
& \mathbf{X}=\left[M^{-1} A M\right] X+\left[M^{-1} B\right] \mathbf{u} \\
& \mathbf{T}=M \mathbf{X}
\end{aligned}
$$

dengan $M$ adalah matriks transformasi

$\mathbf{X}(t)$ adalah vektor state baru dari sistem

$\mathbf{u}(\mathrm{t})$ adalah input dari sistem

$\mathbf{T}(t)$ adalah output dari sistem.

Pada sistem (2), misalkan $\mathbf{X}_{1}$ adalah vektor temperatur yang menyelubungi ruangan dan $\mathbf{X}_{2}$ adalah vektor temperatur panas dari suatu ruangan, maka sistem (2) menjadi :

$$
\left[\begin{array}{l}
\dot{\boldsymbol{X}}_{1} \\
\dot{\boldsymbol{X}}_{2}
\end{array}\right]=\left[\begin{array}{cc}
\boldsymbol{A}_{11} & \boldsymbol{A}_{12} \\
\boldsymbol{A}_{21}(\boldsymbol{t}) & \boldsymbol{A}_{22}(\boldsymbol{t})
\end{array}\right]\left[\begin{array}{l}
\boldsymbol{X}_{1} \\
\boldsymbol{X}_{2}
\end{array}\right]+\left[\begin{array}{c}
\boldsymbol{B}_{1} \\
\boldsymbol{B}_{2}(\boldsymbol{t})
\end{array}\right] \boldsymbol{u}
$$

dengan $A_{11}, A_{12}, B_{1}$ adalah matriks konstan, dan $A_{21}, A_{22}, B_{2}$ adalah matriks timevarying. 
Jika akan dihitung vektor $\mathbf{X}_{1}$, maka vektor $\hat{\boldsymbol{X}}_{2}$ akan diestimasi dari $\mathbf{X}_{2}$ :

$$
\dot{\boldsymbol{X}}_{1}=\boldsymbol{A}_{11} \boldsymbol{X}_{1}+\left[\begin{array}{ll}
\boldsymbol{B}_{1} & \boldsymbol{A}_{12}
\end{array}\left[\begin{array}{c}
\boldsymbol{u} \\
\hat{\boldsymbol{X}}_{2}
\end{array}\right]\right.
$$

Persamaan (4) merupakan model time-invariant.

Selanjutnya, untuk menghitung vektor $\mathbf{X}_{2}$, maka vektor $\hat{\boldsymbol{X}}_{1}$ akan diestimasi dari $\mathbf{X}_{1}$ :

$$
\dot{\boldsymbol{X}}_{2}=\boldsymbol{A}_{21}(\boldsymbol{t}) \boldsymbol{X}_{2}+\left[\begin{array}{ll}
\boldsymbol{B}_{2}(\boldsymbol{t}) & \boldsymbol{A}_{12}(\boldsymbol{t})
\end{array}\right]\left[\begin{array}{c}
\boldsymbol{u} \\
\hat{\boldsymbol{X}}_{1}
\end{array}\right]
$$

Dalam setiap iterasi, hasil $\mathbf{X}_{2}$ pada persamaan (5) dikembalikan sebagai input dari persamaan (4), sampai diperoleh $\left\|\hat{\boldsymbol{X}}_{2}-\boldsymbol{X}_{2}\right\|<\varepsilon$ yang diberikan.

Suatu bangunan dikomposisi atas ruang - ruang udara yang dapat digambarkan dalam sistem differensial dengan orde $n_{i}$. Untuk menghitung waktu dan ketelitian dari simulasi maka harus dipilih suatu himpunan yang terdiri dari orde - orde tereduksi $n r_{i}$.

Adapun rumus untuk menghitung waktu dari simulasi adalah

$$
t_{g}=t_{f}+c \sum_{\text {setiap ruang }} \boldsymbol{n}_{\boldsymbol{i}}^{3}
$$

dengan $t_{f}$ dan $c$ konstanta.

Reduksi yang seimbang akan mempunyai batas error yaitu :

Misalkan $G$ dan $G_{r}$ masing - masing adalah matriks fungsi transfer dari sistem awal dan sistem yang direduksi, maka

$$
\left\|\boldsymbol{G}-\boldsymbol{G}_{\boldsymbol{r}}\right\|_{\infty}=2\left(\sigma_{n \boldsymbol{r}+1}+\cdots+\sigma_{n}\right)
$$

dengan $\sigma_{1} \geq \sigma_{2} \geq \ldots \geq \sigma_{n} \geq 0$ adalah nilai eigen dari matriks singular Hankel. Selanjutnya, $\sigma_{n r}>\varepsilon$ merupakan kriteria yang digunakan untuk memilih order tereduksi $n r$. Jika ketelitiannya sama disetiap ruangan maka toleransi $\varepsilon$ yang sama 
dapat diaplikasikan untuk setiap sistem. Gambar 1 menunjukkan kinerja model tereduksi pada suatu bangunan tertutup.

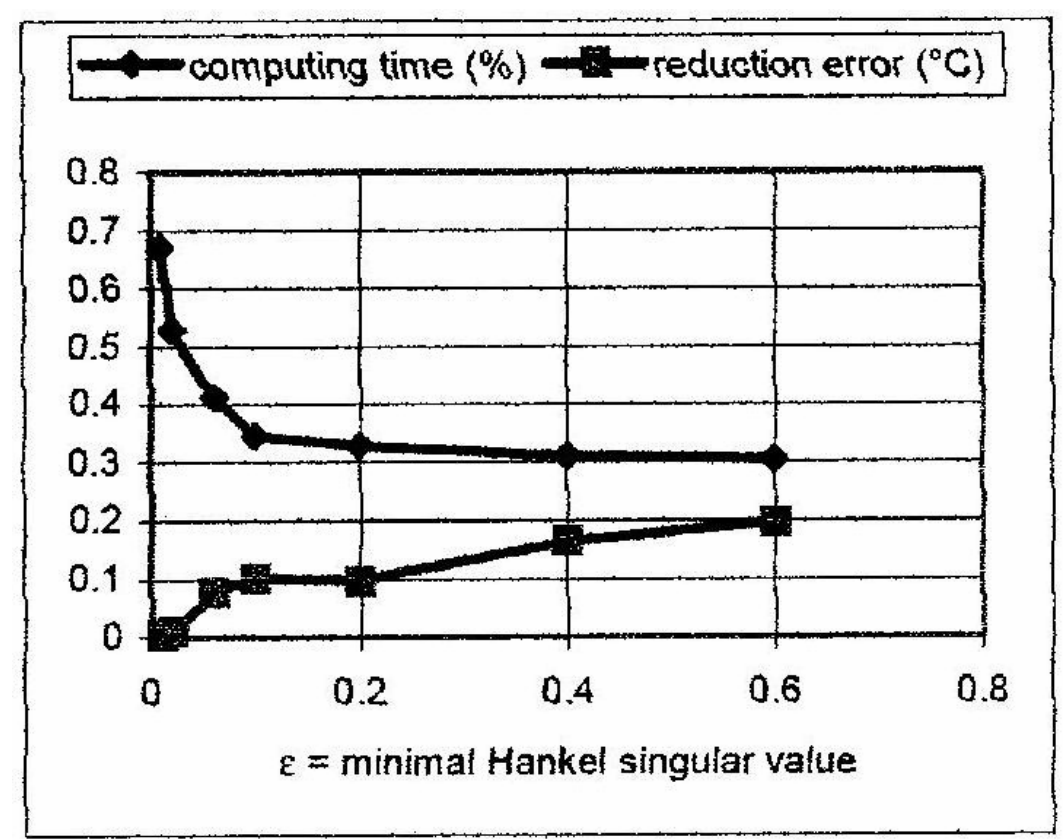

Gambar 1. Kinerja (Performance) Model Terreduksi

Tahap ketiga dari penelitian ini adalah membandingkan hasil pengukuran manual dan simulasi dua model yaitu model standar dan model tereduksi. Pengukuran dilakukan dalam ruang tertutup dan terbuka.

\section{Ruang Tertutup}

Model dari bangunan yang digunakan sebagai eksperimen terdiri atas 5 ruangan (3 kamar tidur, 1 ruang tamu, dan 1 dapur). Pada model ini, model aliran udara tidak digunakan, dan model suhunya adalah model time-invariant.

Gambar 2 menunjukkan hasil pengukuran secara manual selama 7 hari dan simulasi. 


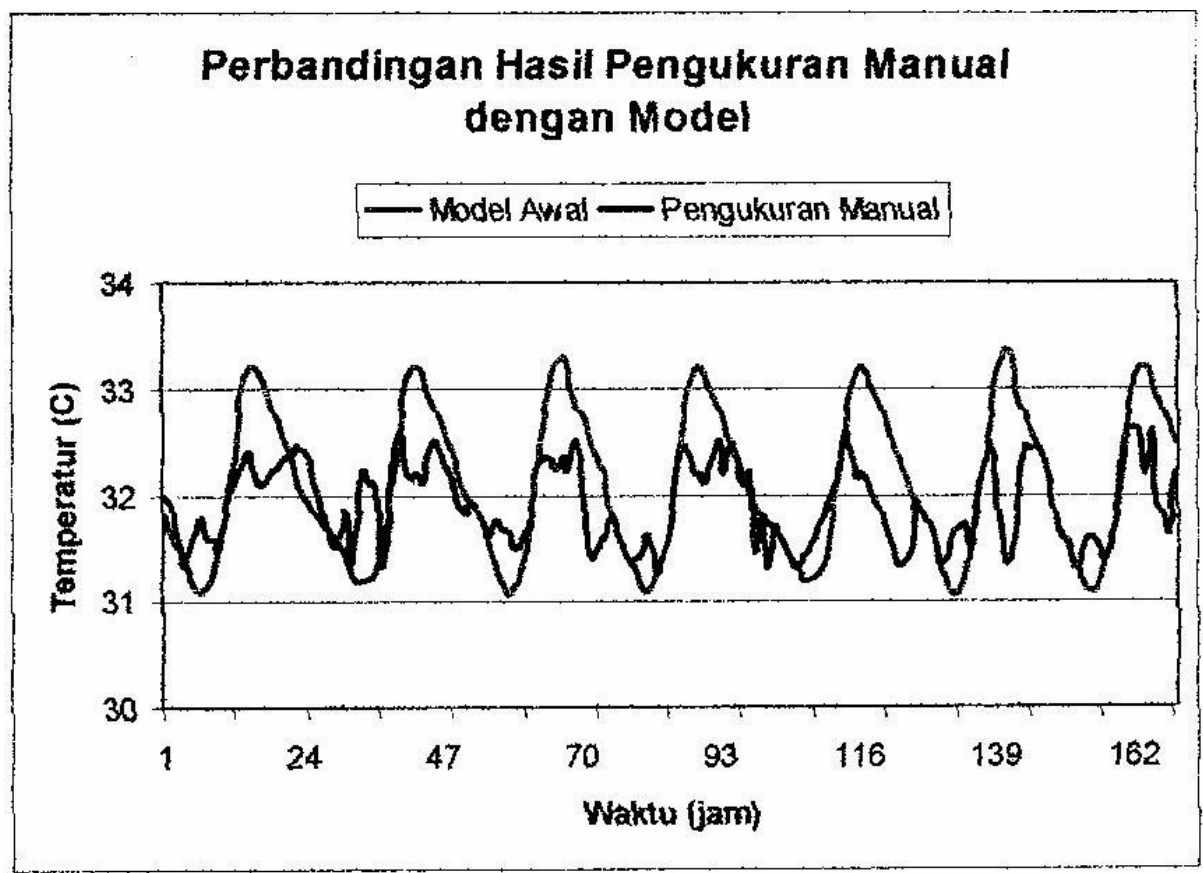

Gambar 2. Perbandingan pengukuran manual dan simulasi

Pada gambar tersebut menunjukkan error model : perbedaan maksimum antara pengukuran dan simulasi adalah $+/-1,2^{\circ} \mathrm{C}$, dengan standar deviasinya adalah $0,55^{\circ} \mathrm{C}$.

Gambar 3 menunjukkan hasil pengukuran secara manual selama 3 hari dan simulasi menggunakan model standar dan model terreduksi. Model awal terdiri dari 5 sub sistem (yaitu 5 ruangan), masing - masing ordenya 33, 36, 37, 68, dan 28. Orde dari model tereduksi masing-masing adalah $8,9,8,13$, dan 4 dengan toleransi $\varepsilon=0,2$. 


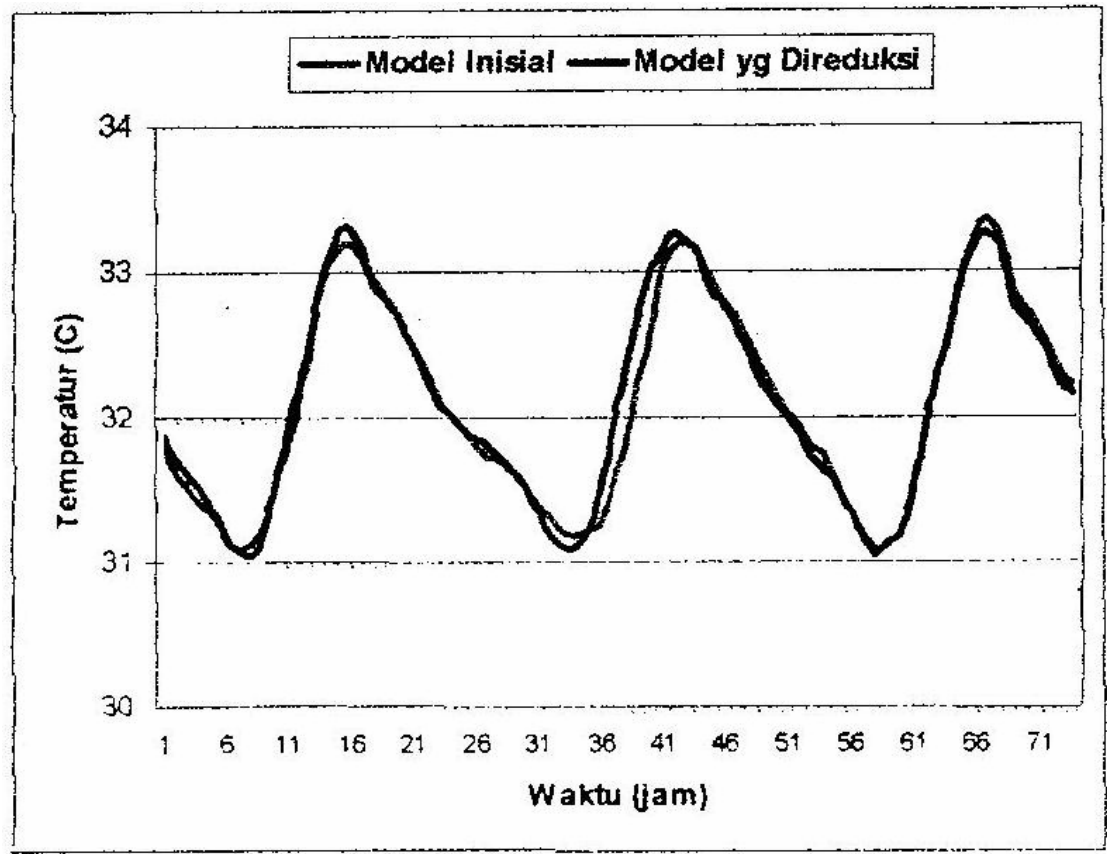

Gambar 3. Perbandingan model awal dan model terreduksi

Hasilnya menunjukkan bahwa maksimum perbedaan model awal dan model tereduksi kurang dari $0,2^{0} \mathrm{C}$.

\section{Ruang Tebuka}

Pada pengukuran temperatur untuk ruang terbuka, simulasi dilakukan dengan 2 metode yaitu

- Menggunakan model awal

Pada model ini dihasilkan sistem dengan order 38, 45, 48, 69, dan 27.

- Menggunakan model terreduksi terpisah

Diperoleh orde sistem adalah 7, 6, 6, 11, dan 5, dengan toleransi $\varepsilon=0,4$.

Kedua simulasi model tersebut dirangkum dalam satu grafik yang tertuang dalam gambar 4. 


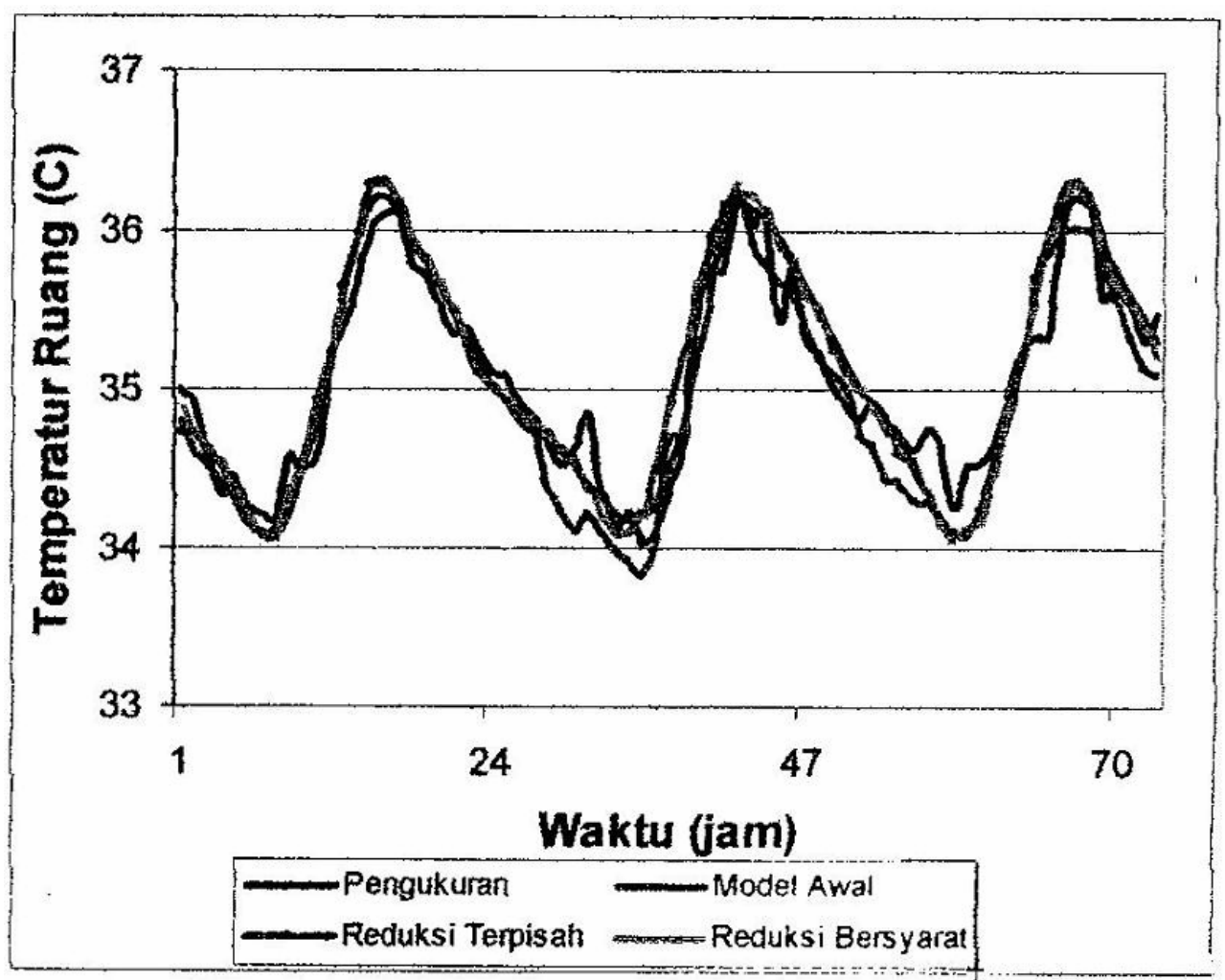

Gambar 4. Perbandingan pengukuran manual, simulasi model standar, dan tereduksi

\section{KESIMPULAN}

Berdasarkan hasil penelitian maka dapat ditarik suatu kesimpulan yaitu

1. Hasil simulasi menunjukkan bahwa model pengukuran suhu yang direduksi menggunakan waktu simulasi yang dibutuhkan lebih cepat 50\% dibandingkan dengan model suhu umum (full order model)

2. Hasil perbandingan menunjukkan bahwa sangant kecil error dari model terreduksi terhadap model standar. Oleh karena itu, dalam penelitian ini telah berhasil ditunjukkan keefektifan dari model terreduksi seimbang untuk sistem time-varying. 


\section{DAFTAR PUSTAKA}

Boyer H, Brau J., dan Gatina, J.C., Multiple model software for air flow and thermal building simulation (A case study under tropical humid climate), Proceedings of Building Simulation, ABPSA Adelaide Australia, 1993, 111-117.

Boyer H, Grade F., Gaina J.C., dan Brau J., A multi model approach of thermal building simlation for design and research purposes, Journal Energy and Buildings, 28(1) (1998), 71-79.

Boyer H., Lauret P., Adelard A., dan Mara T.A., Building Ventilation : a pressure airflow model computer generation and elements of validation, Journal energy adan Buildings, 29(1999), 283-292.

Boyer H., dan Thierry Berthomieu, Time-Varying Linear Model Approximation : Application to Thermal and Airflow Building Simulations, Eight International IBPSA Conference, Eindhoven, Netherlands, 2003.

Palomo E., Dautin S., Yahia A., dan Deqeu F., Building Thermal Model Ruduction : Improving Existing Methods by Taking Spectral Input Characteristics into Account, Proceeding of IBPSA, 1997. 
